\title{
On the Development of Communicative Understandings: An Early Strategy for Interpreting and Responding to Messages
}

\author{
Marilyn Shatz \\ University of Michigan
}

"Words are but the shadow of actions."

Democritus

\begin{abstract}
Young children's apparently sophisticated understanding of language is explained by a simple heuristic which produces responses fortuitously appropriate to many of the messages directed to them. Specifically, the strategy recruits action responses to language unless some element, either linguistic or nonlinguistic, indicates otherwise. Two experiments tested for the existence of the heuristic by examining the responses of children, 19-34 months of age, to sentences susceptible of more than one interpretation. In the first experiment such sentences were spoken in as neutral a context as pussible. In the secund, the same sorts of sentences were presented in contexts supporting either action or informing responses. The results of both experiments indicate that young children interpret and respond to language in terms of an action-based strategy. Moreover, the observed effects of context show that even young children engage in a continuous, context-sensitive process of interpretation. The data are discussed with regard to speech act theory and its role in a developmental theory of understanding.
\end{abstract}

Young children are quite adept at behaving in ways that make their parents believe they understand what is said to them (cf. Huttenlocher, 1974). For example, a parent who wanted her child to put a doll in a toy swing said, "Why don't you put her on there?" The child placed the doll on the swing. This same child was barely able to produce two-word utterances. Observations like this have sometimes been taken as evidence that young children have extensive competence in the linguistic code, the set of formal rules which governs the production and comprehension

This work is based on a doctoral dissertation submitted in 1975 to the University of Pennsylvania. I thank Rochel Gelman, Lila R. Gleitman, and Henry Gleitman for their enthusiastic encouragement and advice throughout the project; Elissa Newport for her many useful comments on earlier versions of the manuscript; Mark Baltin and William Labov for helpful discussions on pragmatics; and all the mothers and children who participated in the studies. Marjorie Horton, Ivy Kuhn, and Mary Hope Lee provided invaluable assistance in collecting and coding the data. The research was supported by an NICHHD grant (HD527444) to Rochel Gelman and an NICHHD traineeship (HDOO337) to the author. Reprint requests should be sent to Marilyn Shatz, Human Performance Center, University of Michigan, 330 Packard Road, Ann Arbor, MI 48104. 
of grammatical sentences, but that this competence is not manifest in production simply because of "performance" deficiencies. An alternative view is presented here: Children's apparent understanding results not from their sophisticated decoding of the linguistic signal but from the way the human processing system generally constructs interpretations of communicative interactions and from the specific kinds of preferred representational heuristics young children bring to the task of understanding and responding to the language spoken to them.

This paper provides a theoretical account of the child's early system for responding to linguistic interactions and possible sources of development in that systcm. Two expcriments which tested the response model by examining responses to utterances that can be interpreted in more than one way are presented as evidence for the system.

\section{A DEVELOPMENTAL PROCESSING MODEL OF INTERPRETATION}

\section{Understanding and Misunderstanding Messages in Context}

Participants in conversations use their messages to create a shared mental space, producing in their listeners awareness of some part of their external or internal world. Understanding involves the listeners' representing the messages sent to them in just the way that the senders intended them to be represented. Misunderstanding occurs when listeners represent messages in ways other than those intended. But whether or not the representations they arrive at are the ones intended, listeners carry out processes of interpretation-or assignments of meaning. In doing so, they take account of a variety of the elements - both linguistic and nonlinguistic-available in communicative situations to construct the most plausible interpretations of what they hear as well as responses appropriate to those interpretations.

Moreover, communicative interactions occur in the context of participants' broader, continuous representational processes, and interpretations of those interactions are integrated with them to sustain consistent world views. (See Bransford \& McCarrell, 1974; Gunter, 1974; and Rommetveit, 1974; for representative discussions of adults' integrative processes leading to interpretations of language.) Language, then, does not always have to express fully and unambiguously a speaker's intentions. Indeed, a language which did so would be unnecessarily inefficient given that language users tap other sources of information as well in the communicative process. Each of the sources of information constrains the set of acceptable interpretations a message can convey. The more the conversational participants share those sources of information the more they are likely to understand each other.

In creating messages, speakers regularly take into account the other sources of information they expect their listeners to have, but they may 
take account of certain elements while their listeners take readings of different elements or even different readings of the same elements. The readings taken depend, of course, on the knowledge the participants bring to the situation. These internal conditions further constrain possible representations of messages, and it is in terms of these internal conditions through which information must be "filtered" that adults and children may differ. Children may take readings from the same domains as adults, but what they can process and how will depend on the representational systems they have thus far constructed. Their abilities at different ages are an empirical issue, which recent work in language acquisition on comprehension and pragmatics has begun to address (e.g., Atkinson, Note 1; Bates 1976a; Bloom, 1974; Dore, 1977; Garvey, 1975; Huttenlocher, 1974; Keenan and Klein, 1975; Macnamara and Baker, 1977; Shatz and Graves, Note 7). Yet, even unsophisticated children actively and continually represent to themselves the events and relationships in their world and take readings from a variety of sources to interpret messages, although their readings may be impoverished, or at least different, compared to those of adults.

While children's readings and hence their representations may differ from those of their parents, the consequent misunderstandings may not be obvious, for children may produce responses that are appropriate both to their representations and to those intended by their parents. For example, if the child described above knew, as did the adult, that "why don't you" questions can function as requests for action, and if the child also knew how to decode the case relationships expressed by the grammar of the sentence, then the appropriate response would have been a valid sign of understanding; but the same response could have been generated even if the child knew only that dolls typically go in swings (not vice versa) and that language is an invitation to produce some plausible activity on his or her part. Although the child would have made the same response, leading the adult to infer understanding, he or she would in fact have misunderstood. If parents' most frequent messages to their children are just the kind that can be answered on the basis of such simple response strategies, then parents are likely to overestimate their children's understanding.

\section{The Messages Directed to Young Children}

Mothers' messages typically are expressed about equally often as declaratives, questions, and imperatives (Broen, 1972; Newport, 1976; Snow, 1972). This does not mean, however, that parents are engaged equally often in getting their children to do things and in giving and asking for information. Sentence mood is not a wholly reliable indicator of intention in English. For example, questions ("Can you shut the door?") and 
declaratives ("The window is open.") can both function as directives in the appropriate contexts. Several researchers have shown that mothers regularly use such indirect forms to elicit action from their children (Holzman, 1972; Remick, Note 4; Shatz, 1978; Shatz, Note 6). Even the bulk of the complex sentences spoken to young children by both mothers and older children serves to direct the activities of the listener (Gelman \& Shatz, 1977). It would seem, then, that speakers often intend their utterances, regardless of their form, to elicit action responses from their young listeners.

There is some evidence that young children appear to understand "indirect directives," sentences spoken with the intention of getting the listener to do something but which do not explicitly convey that intention syntactically. Shatz (1978) videotaped five mothers and their children, aged 19-28 months, as they played with and talked about a toy in a natural conversational situation at home. The mothers' requests for action which were expressed by the direct imperative form were not more likely to elicit action from their children than were those expressed indirectly. Indeed, when the children responded meaningfully at all (as opposed to ignoring their mothers or just looking confused), they almost always responded with action.

One explanation of the children's behavior is that they are very sophisticated about reading speaker intentions from the language they hear. Under this interpretation, they derive the literal meaning of an utterance from the syntax and semantics and then, when a literal reading seems unreasonable in the context spoken, they infer alternative interpretations, namely, that action is being requested. [Searle (1975) and Clark and Lucy (1975) suggest this sort of procedure for adults.] Given this interpretation, parents' beliefs that their children are very clever at understanding what is said to them seem justified. However, granting children such sophisticated competence may be unwarranted.

\section{The Processing Heuristics of the Young Child: Joint Activity and the Action Procedure}

What kinds of knowledge do young children bring to the task of representing messages? Very young infants notice verbalizations directed to them, and they produce activity in return (Bates, Camaioni, \& Volterra, 1975; Escalona, 1973). Their response behaviors such as eye contact, smiling, and babbling may be nothing more than preprogrammed acknowledgments of the existence of an animate being, but they are important precursors to a communicative system depending on sequenced interactions between participants (Bruner, 1975). One of the earliest knowledge sources underlying an interpretive system, then, is a social one: knowing how to recognize that an interaction has begun, that it is 
directed at one's self, and that it is maintained by responding to it. Also, from their early months, children are busily learning, via their active manipulation of the world around them, the properties of objects and the kinds of actions that can be performed on them (Piaget, 1952). Much of their first representations of the world are likely to be in terms of these action relationships.

These two aspects of the young child's world, social interaction and action on objects, are first brought together when parent and child engage each other in some activity involving objects in the world, for example, placing a rattle in the infant's hand and his subsequent release of it. In these circumstances an external object becomes the focus of joint activity and joint attention (Bruner, 1975). Thus, children come to expect that certain of their actions are somehow joined with those of their parents and that the choice of action is further constrained by the object under mutual consideration.

During these joint activities, parents may utter the words for the objects acted upon and the actions performed. Children who already know that verbalizations are a means to creating joint attention and that words are often accompanied by designative gestures like pointing and showing begin to recognize that words act referentially, ${ }^{1}$ as designators of the objects to be acted upon or the actions to be performed. The function of the interaction is similar both for the child who has learned that words have a referential purpose and for the child without such knowledge: Interactions create a joint focus of activity. For the child without referential word knowledge, language may function solely as an attention getter; for the child with such knowledge, the parent's words specify the activity or object over which the interaction is to take place.

However, even for the more knowledgeable child, the heuristic of representing messages fully in terms of objects to be acted upon and actions to be performed results in representations that need not include an explicit concept of speaker intention. Rather, the fact of an interaction including language of necessity involves a call for action. The simple response procedure (A) then follows directly from the nature of the interpretation.

(A) Respond with action a or with an action on some object $o$, where a and o are members of the set $\mathrm{S}$ the elements of which consist of actions or objects identifiable from the speech stream.

Thus, children are granted a system for producing responses to language which presupposes only minimal knowledge of any of the formal rule sys-

\footnotetext{
${ }^{1}$ The question of reference has a long history as a philosophical problem, and I do not mean to make the acquisition of a notion of reference appear to be trivial. One can, however, distinguish an abstract notion of reference class from reference to a particular object in context. It is this latter use of reference that is most obviously facilitated by joint attention and activity. See Bates (1976b) and Bruner (1975) for similar views on understanding reference in context.
} 
tems that supposedly constrain adults' interpretations of sentences (cf. Grice, 1975; Katz, 1972, 1977; Searle, 1975). Their strategy is not a processing "short cut" used by a communicator possessing a full catalog of speaker intentions. It is a heuristic for dealing with a poorly understood source of information. Like other early strategies (Clark, 1973; Wilcox \& Palermo, 1975), it provides a means for entering in an orderly way the complexity of linguistic interaction, by dealing with language in terms of the potential for immediate action.

\section{From Action Procedure to Stop-Action Procedure}

There are several ways in which the child can begin to develop a more diversified response system. I suggest a few here that follow from the kind of processing system proposed earlier.

The simplest communicative situation in which young children find themselves is one in which the language directed to them refers to present objects or actions possible in the here and now. The physical context then fully supports their readings of the language. However, when children hear words that refer to an absent object, their action response strategy will still be appropriate only if the object is obtainable nearby, and they have the memory capacity to represent the object internally and to carry out a search and retrieval operation for it. Children as young as 14 months have been observed doing just this (Huttenlocher, 1974). However, it may be that the objects talked about cannot possibly be physically brought onto the scene. Children may hear utterances like "You look like your Daddy." If Daddy is in the room, the child is likely to look at him or perhaps even climb up on his lap, but, if Daddy is not at home, the action strategy fails, providing feedback about the inadequacy of an action interpretation and response procedure. Children must then begin to search for a new meaning to interactions besides plausible activity.

The experience of joint attention plus the breakdown of the action strategy lead to a recognition that attention can be mutually focused on the internal representations of an object and not just on its external embodiment. This recognition underlies the discovery that talking can refer to thoughts about seeing and doing (or having seen and having done) as well as what is being seen and done during the interaction. ${ }^{2}$ A different type of response is required in this sort of situation. The child still must acknowledge the interpersonal contact and give recognition of its focus. In some cases, symbolic actions may suffice (one can mime throwing a ball even if

\footnotetext{
${ }^{2}$ This is not to imply that communication breakdowns necessarily lead to recognition of mutually held internal representations. There may be several cognitive prerequisites for the development of such understanding, e.g., the development of the symbolic function (Piaget, 1962). Communication breakdowns early in the child's interactional history may not be able to trigger recognition and hence may foster no growth in the response system.
} 
no ball is present), or one can use words which announce that the listener understood what it was he or she was supposed to be thinking about. A repetition of the words used earlier by the speaker of the original message can serve this purpose as can a "yes" or a head shake. [Scollon (1977) provides examples of such responses.]

Not only constraints of the physical world but also interpersonallinguistic contexts provide information as to the appropriateness of action responding. Middle-class parents, at least, engage their children in a variety of language games or routines, many of which are a variation of the "What is this" game. [See Gleason \& Weintraub (1976) on routines.] Again, joint attention is focused on an object, and often these routines are embedded in interactions requiring action. The following sequence is typical of mothers and children in their second year:

Mother: "Do you want a cookie?"

(Child runs to the cookie drawer. Mother takes out a cookie and holds it above the child's reach.)

Mother: "Can you say cookie? Say cookie. What is this?"

Child: "Cookie."

Mother: "That's right. Cookie."

The child originally acts on the mother's words, but the mother communicates that something more is expected. The child learns that words like "say" and "what" function as markers signaling when he or she must do something besides act, namely, produce the designatory labels for the objects under common consideration.

In another variation of the routine, a linguistic marker specifies the kind of action response required. Very young children who speak little or not at all have already learned that "Where is the __?" takes a showing response like pointing or holding out (Fraser, Bellugi, \& Brown, 1963; Huttenlocher, 1974).

These examples suggest that response procedure (A) applies unless there is some element in one of the contexts that implies otherwise. As children get feedback on their behavior and become more adept at reading the contexts, they learn when not to perform action or when action alone will not suffice. More formally, then, let $\mathrm{S}$, as before, be the set of actions or objects identifiable from the speech stream, and now let $\mathrm{L}$ be the set of constraint markers identifiable from a reading of linguistic input, and $C$, the set of constraint markers identifiable from readings of the physical, interpersonal, or social context. Procedure (A) can now be amended to include the notion of stop-action markers.

(B) Respond with action a or with action on an object o unless 1 or $\mathrm{c}$ is present, where a and $o$ are members of the set $S, 1$ is a member of the set $L$, and $c$ is a member of the set $\mathrm{C}$. 
When very young, children can identify few of these markers, but, as they learn them, they gradually organize them under new response procedures which result in an ability to disassociate messages from the performance of immediately possible action. The proposed response procedure accounts for children's behavior and grants them little in the way of sophisticated knowledge. Need we grant young children more? The experiments which follow are addressed to just this question.

Before proceeding, a word on experimental strategy is in order. The postulated system describes a child who starts out responding to language by performing immediately possible actions and who gradually learns stopaction markers and develops a more elaborate response system. For children who recognize language only as a call to attention, possible actions may be merely turning toward the speaker or some sort of undirected motor activity. By the time children know the names of some objects, they may already have learned some stop-action markers or at least some markers for specific actions, like where mentioned earlier. Thus, it would be difficult to find and test children who have learned virtually nothing about stop-action markers. The alternative is to look at the developing system and to infer the nature of the earliest stages from the course of development. This is the sort of enterprise engaged in below. The children who served as subjects in these studies had response systems more elaborate than the postulated one. The intention was not to describe fully those more elaborate systems, but to discover from the way the children used them in a variety of circumstances what their origins might have been and how they might have become what they were.

\section{EXPERIMENT I: RESPONSES TO LANGUAGE UNDER "NEUTRAL" CONDITIONS}

Sentences which can be interpreted as requests for action or as requests for or statements of information were directed to children by the experimenter who was neutral with regard to the interpretation she expected her listeners to place on the utterances. The utterances were spoken in a context which, as nearly as possible, made neither interpretation more plausible than the other. Of course, a truly neutral context was unlikely since exactly what contextual elements might contribute to a particular listener's interpretation were unknown. The obvious biases were eliminated by using a speaker other than the child's mother and giving a varied set of utterances in the presence of toys that could be acted on. The experimenter also tried to avoid intonations or nonverbal behavior which would support one interpretation over another. A listener knowing that these sorts of utterances can convey either directive or informational intentions and bringing no response bias to such a neutral situation should randomly select one of the two responses befitting either of the possible interpretations. In contrast, the proposed theory generates the following predictions. 
(a) Young children will produce a preponderance of action responses even though the intentions of the speaker are neutral with regard to how the listener is to take the sentence.

(b) Action responses will predominate over nonaction responses for all types of sentences that can convey a directive reading, regardless of whether they do so directly or indirectly. The tendency to produce action responses should not differ with sentence type.

(c) The direction of response development in neutral contexts will be away from action responding and toward an increased use of responses based on informational interpretations. Thus, the younger (or less sophisticated) the child the more action responses produced, relative to the total production of meaningful responses.

(d) The movement away from action responses is not necessarily produced by the acquisition of a unique set of linguistic elements marking speaker intentions.

The purpose of the first experiment was to test these four predictions by directing a variety of utterances to children with varying degrees of language ability in as neutral a context as possible.

\section{Method}

Design. Children were assigned to one of three language sophistication groups (low, middle, or high) on the basis of their productive language ability as measured by their mean length of utterance (MLU) in words.

Each subject was required to respond to eight different types of sentences. The full protocol consisted of five trials of each sentence type for a total of 40 test sentences. The trials for a particular sentence type differed from one another only with regard to the lexical items which related the sentence to the set of toys the child was playing with at the moment. The sentences were presented in five blocks of eight sentences each, consisting of one trial for each of the eight sentence types. Each of the five blocks utilized a single set of lexical items which referred to one of the five sets of toys presented one at a time to the child. The design is summarized in Table 1. The order of sentence types within each

TABLE 1

Design for the Neutral Context Experiment

\begin{tabular}{|c|c|c|c|c|c|c|}
\hline \multirow[b]{2}{*}{ Sentence type } & \multicolumn{6}{|c|}{ Lexical item } \\
\hline & $\begin{array}{c}\text { Fit } \\
\text { Balls/truck }\end{array}$ & $\begin{array}{l}\text { Put (go) }{ }^{a} \\
\text { Dog/car }\end{array}$ & $\begin{array}{c}\text { Fit } \\
\text { GirVhorse }\end{array}$ & $\begin{array}{c}\text { Put (go) } \\
\text { Man/plane }\end{array}$ & $\begin{array}{c}\text { Put (go) } \\
\text { Chair/house }\end{array}$ & Trials \\
\hline 1. Imperative & $\mathrm{x}$ & $\mathrm{x}$ & $\mathrm{x}$ & $\mathrm{x}$ & $\mathrm{x}$ & 5 \\
\hline 2. "Can you ..." & $x$ & $\mathrm{X}$ & $\mathrm{X}$ & $\mathrm{X}$ & $\mathrm{X}$ & 5 \\
\hline 3. "Why don't you ..." & $\mathrm{x}$ & $\mathrm{x}$ & $\mathrm{x}$ & $\mathrm{X}$ & $\mathrm{x}$ & 5 \\
\hline 4. "Do you want to ..." & $\mathrm{X}$ & $\mathrm{X}$ & $\mathrm{X}$ & $\mathbf{X}$ & $\mathrm{x}$ & 5 \\
\hline 5. "Can" + noun & $\mathrm{X}$ & $\mathbf{x}$ & $\mathrm{x}$ & $\mathrm{x}$ & $\mathrm{X}$ & 5 \\
\hline 6. "Does" + noun & $x$ & $\mathrm{x}$ & $x$ & $x$ & $\mathrm{X}$ & 5 \\
\hline 7. Declarative & $\mathrm{X}$ & $\mathrm{x}$ & $x$ & $\mathrm{X}$ & $\mathrm{x}$ & 5 \\
\hline 8. "May you'" & $x$ & $\mathrm{x}$ & $\mathrm{X}$ & $\mathrm{X}$ & $x$ & 5 \\
\hline Blocks & 1 & 1 & 1 & 1 & 1 & $\begin{array}{l}40 \text { sentences } \\
\text { in all }\end{array}$ \\
\hline
\end{tabular}

"Go" was the verb used with Types 5, 6, and 7 . 
block was varied and the order of presentation of toys and related blocks of sentences was randomized across children. [See Shatz, (Note 5) for further details.]

Subjects. The subjects were 11 female and 7 male middle-class children aged 19-34 months, with a mean age of 27 months. They were recruited on an individual basis through acquaintances of the experimenter.

Toys. Each of the five sets of toys included several instances of each object, for example, four trucks and five balls of varying shapes and sizes for one set. The toys were selected to represent words young children are most likely to comprehend (Goldin-Meadow, Seligman, \& Gelman, 1976).

Sentences. The eight sentence types were selected to assess the children's responses to sentences that differ with regard to syntactic construction, the nature of the conditions under which they are interpreted as requests for action, and the general likelihood of their being interpreted as such by adults. The sentence types 2 through 7 listed in Table 1 can function as "indirect directives" in English. While their mood does not directly specify directive intent, they embody a variety of different conditions that can be questioned or emphasized in order to convey it (cf. Gordon and Lakoff, 1971; Searle, 1970; 1975). The general notion behind the Searle approach is that speaker and listener share knowledge about both the topic at hand and each other. When a sentence is uttered which directly asks a question or states something already known, that utterance cannot be intended literally since a speaker cannot appropriately request information he or she already has or give information already known (Grice, 1975). Furthermore, in a context in which the act specified in the proposition is yet to be done and it is likely that the speaker wants it done, the listener infers that the speaker intends a request for action. Thus, type 2 questions the listener's ability to perlorm the act; type 3, the reasun for not doing it; type 4 , the listener's desire to do it; type 5, the possibility of the act being done; type 6 , the truth of the proposition; and type 7 asserts the truth of the proposition. Sentence types 1 and 8 are controls in that type 1 is the imperative which directly expresses the directive intent and type 8 is a question form similar in syntax to type 2 (inverted modal + you) which rarely functions as an indirect directive in English.

The variety of these sentence types allowed for the testing of the hypothesis that different conditions for creating directives are learned at different times as well as for the testing of hypotheses about the children's use of surface markers like "you" as cues to responding.

Procedure. During an initial "get-acquainted" session in the subject's home, the child's speech was tape-recorded in order to obtain a corpus on which to compute an MLU. A simple comprehension test (cf. Huttenlocher, 1974) was administered to determine whether the children knew the names of the toys to be used in the later session. Only the youngest child failed several items and was later shown only three sets of toys.

Within a week, the experimenter returned to the subject's home and, after a short warm-up play session between mother and child, began the experiment by giving the child the first of five bags containing a set of toys and speaking the sentences associated with that toy. The test sentences were interspersed among filler sentences that ty pically commented on features of the toys or some irrelevant behavior of the child. At least two filler sentences separated any two different test sentences. The experimenter tried to utter the test sentences at times when the child's attention seemed focused on the play situation, but, if the child was just about to touch the toys or had already begun to perform an action like the one in the test sentence, the experimenter delayed uttering the sentence. If the child did not respond to the first instance of a test sentence, then it was repeated once. Particularly with the younger children, two attention-getting devices were occasionally used: calling the child's name and placing toys in the child's line of sight before the utterance was spoken. The experimenter also tried to minimize nonverbal cues like pointing at the toys and reinforcement of specific responses. General reinforcements like "You're a good boy!' wer: interspersed throughout the session. If a child became inattentive or uncooperative with one set of toys, a new bag was brought out even though a block of sentences had not been completed. Thus, the mean number of sentences heard was 35 with a range from 17 to 40 . The standard time for an experimental session was about $30 \mathrm{~min}$. 
Equipment. Tape recordings were made using a Sony 180 portable tape recorder and an EKG D 109 microphone. The experimental sessions were videotaped using a Sony AV 3600 vidcorecorder, an EKG D 109 microphone, and a Concord CTC 33 camera equipped with a zoom lens.

\section{Data Analysis}

Computation of $M L U$. The audiotapes of the children's speech were transeribed by the author and a mean length of utterance in words was computed for each child according to the procedure in Shatz and Gelman (1973). The children were then assigned to one of three groups depending upon their MLU. The low group of six children had a mean MLU of 1.4 and a range from 1 to 1.8 words per utterance. The six children in the middle group had a mean MLU of 2.4 and a range from 2 to 2.7 words. The six in the high group had a mean MLU of 3.5 with a range from 3.2 to 4.0 .

Coding of responses. Table 2 summarizes the categories of children's responses to test sentences. There were three basic kinds of categories of responses: meaningful responses where the children produced some behavior (verbal or nonverbal) that indicated relatively unambiguously the minimal meaning they had to have extracted from the message in order to have considered producing that response: ambiguous responses where the children's behavior indicated that they had heard and had responded to the utterance but it could not be determined with enough confidence how they had interpreted it; and finally indeterminate behaviors that were responses only in the sense that they described what the children were doing (or not doing) after the utterance occurred, but it could not be determined whether these behaviors were contingent on the speaking of the utterance. The scoring took account of both the child's verbal and nonverbal behavior as well as the temporal relationship between the two. Thus, for any given category, both kinds of behavior had to support the assignment of the combined response behaviors to that category.

The two subcategories of meaningful responses, action and informing, are the most important for our concerns here. For action responses, the minimal assumption of meaningfulness is that children see speech as signals for action on the objects made salient by the linguistic message itself or perhaps by prior activity. There is no assumption that children have a notion of speaker intention, only that they recognize the need to respond to speech with some activity. Informing responses assume that children have learned (a) that speech can be an invitation to direct their attention (and not necessarily actions) to some external object or event or (b) that speech can focus joint attention on internal representations as well as external objects and activities. Thus, action responses are not necessarily responses of activity without any verbalizations, nor are informing responses necessarily any verbalization without accompanying action. The names assigned to these two categories refer to the nature of the children's interpretations that can be inferred from their response patterns and not directly to the nature of the responses themselves.

In addition to the criterion that the child had to perform or begin to perform the action requested, two further critcria had to be fulfilled before a response was counted as ac. tion. First, the child had to appear to do the action in response to the utterance and not appear to be about to do it anyway. Second, what the child said in accompaniment to his or her action could not suggest anything other than that he or she had taken the utterance as a call to action. For example, children were credited with action responses if they answered "Can you put the ball in the truck?" with a "yes" and then proceeded to do the action. The decision to count this pattern as action responding was based on its similarity to the "okay" followed by action pattern that the children often produced." However, if they did the action and then said something like, "See, it fits," then they were considered to have done the action only to test out or show its feasibility and were credited with informing responses. Likewise, action followed by "yes" was also

"It is possible that a child learns that some types of sentences take a "yes" response as an accompaniment to action responses before learning that such sentences also can have informational interpretations (cf. Shatz, 1978.) 
TABLE 2

Categories for Coding ChILdREN's Responses in EXPERIMENTS 1 AND 2

Category of response Description

\begin{abstract}
Meaningful responses
Action

Action apparently in response to and appropriate to directive interpretation, at least with regard to form (even if not a completed action on the correct referent). Any accompanying verbalization to be consonant with action categorization and not suggestive of alternative interpretation.

Informing

(a) Verbal responses appropriate to the syntax of the speaker's utterance and unaccompanied by action. (b) Verbal responses accompanied by or following action when verbalizations report on tests of the feasibility of action. (c) Attentive looking in response to declaratives.
\end{abstract}

\author{
Ambiguous responses \\ Negative \\ Contradictory \\ Requests for clarification
}

Indeterminate behaviors Ignoring

Louking

Unclear (a) Verbal "no" without any attempt at action. (b) Nonverbal refusal; turning away, throwing toys, etc.

Inconsistencies between verbal and nonverbal behavior, e.g., a verbal "no" accompanied by attempted action.

Verbalization requesting a repetition of or more information about the action specified in speaker's utterance without accompanying action.

No evidence, either verbal or nonverbal, that speaker's utterance was processed or even heard.

Looking blankly at speaker, possible handling of toys, but no evidence of arrival at an interpretation or response to speaker's utterance.

(a) Verbalizations unintelligible, actions unclear. (b) Action accomplished but may have been begun independently before speaker's utterance. (c) Action accomplished but possibly unduly influenced by speaker's nonverbal behavior.

counted as informing since again there was the possibility that the action had been performed as a test of feasibility. Of course, relevant verbalizations unaccompanied by relevant action responses were counted as informing responses as were instances of attentive looking in response to declaratives. ${ }^{4}$

Not all the verbalizations the children produced were relevant to the categorization judgments. Some seemed to occur just as accompaniments to the actions the children performed and may even have aided their performance (Luria, 1964; Piaget, 1926). For example, in response to "Why don't you put the man on the plane?" one child did the action and said, "Go in there" as she did so. The children also sometimes asked questions such as "This one?" or "In here?" to confirm their already-begun action responses or the objects to be acted on. Such verbalizations typically did not influence categorization decisions. [See Shatz (Note 5) for further details on coding.]

${ }^{4}$ The attentive looks were qualitatively different from the uncomprehending stares counted as "looking" under indeterminate behaviors (see Table 2). 
Coder reliability. All of the responses were initially coded from the videotapes by a research assistant. The author separately coded 10 randomly selected tapes, and percentage agrecment scorcs werc computed. The overall percentage agreement was $88 \%$ with a range from 76 to $100 \%$. All the tapes were then rechecked and disagreements were discussed and resolved.

Measures. The categorized responses were used to compute two measures for each child for each sentence type. The first measure is the proportion of all possible codings (including indeterminate responses) which were action (A) responses. Thus, an A/T (for Total) score of $80 \%$ for a child who was presented with five trials of a sentence type indicates that he or she responded with action four times out of five. The second measure is a proportion of only the meaningful (M) responses: the proportion of action and informing responses that were action responses. Thus, an $\mathrm{A} / \mathrm{M}$ score of $100 \%$ for the above subject would indicate that on the five trials he or she had responded four times with action and had not responded the fifth time with an informing response, whereas an $\mathrm{A} / \mathrm{M}$ score of $80 \%$ would indicate that the nonaction response had been an informing response.

\section{Results and Preliminary Discussion}

\section{The Predominance of Action Responding}

The first prediction stated that young children would produce a preponderance of action responses even in the "neutral" context. Across all sentence types, for just the action and informing responses, an average of $91 \%$ of them were action and only $9 \%$ were informing. For each of the 18 subjects, at least $75 \%$ of the action and informing responses were action responses. Not only did action responses predominate over informing responses, they predominated over all other behaviors. The average percentage of action responses over total responses was $62 \%$. Fourteen of eighteen children produced action responses to more than half of all the utterances they heard. Sixteen percent of all the action responses were of the "yes" followed by action type. Even if all these responses had been coded as informing instead of action, the bias for action responding would still have appeared.

\section{The Effect of Sentence Type}

The second prediction stated that all types of sentences should elicit a high proportion of action and that the amount of action elicited should be independent of the particular type of test sentence. The first column of Table 3 shows that more than half the responses elicited by each sentence type were action responses. Neither a Friedman two-way analysis of variance on the rankings of the $\mathrm{A} / \mathrm{T}$ scores $\left[X_{\mathrm{r}}{ }^{2}(7)=6.36, p<.4\right]$ or individual $t$ tests testing the mean $\mathrm{A} / \mathrm{T}$ score for each sentence type against the grand mean revealed any significant difference among sentence types. Thus, on the basis of the A/T measure, no one sentence type regularly elicited more action behaviors than did the other types.

The second column of Table 3 shows that, for each of the eight sentence types, the proportion of action responses to meaningful responses was at least $80 \%$. Only one child in the high-MLU group produced more informing 
responses than action responses for one sentence type ("Can you ..."). Thus, each sentence type elicited a preponderance of action responses over informing responses for virtually all the children. Moreover, a Friedman two-way analysis of variance on the rankings of the $\mathrm{A} / \mathrm{M}$ scores showed no significant differences among sentence types $\left[X_{r}^{2}(7)=11.37\right.$, $\mathrm{p}<.2]$.

\section{Development Away from Action Responding}

The third prediction was that the direction of response development would be away from a high proportion of action responses toward an increase in informing responses. The mean $\mathrm{A} / \mathrm{M}$ scores were 98,93 , and $83 \%$ for the low-, middle-, and high-MLU groups, respectively. There was little overlap of scores among the groups, and the probability of obtaining that distribution of scores is less than .001 (Kruskal-Wallis $H(2)=20.10$ ).

Furthermore, two subjects in the low-MLU group produced only four informing responses out of a total of 194 responses; five subjects in the middle group contributed 11 informing responses out of 220; and in the high group six subjects produced 28 out of 224 . The predicted result was obtained despite the fact that easily producible responses like looking attentive to a declarative or just nodding one's head "yes" were both allowed as informing responses.

\section{Patterns of Response Development}

The last prediction was that there is no unique set of markers that is acquired in an orderly fashion which determines the movement toward informing responses. It was noted earlier that only one child, for one sentence type, produced more informing responses than action responses. Thus, the hypothesis that the young child's responses are controlled by the

TABLE 3

Average Percentage of Action Responses by Sentence Type, Experiment 1

\begin{tabular}{lcc}
\hline & \multicolumn{2}{c}{ Measure } \\
\cline { 2 - 3 } Sentence type & $\begin{array}{c}\text { Action/ } \\
\text { total responses }\end{array}$ & $\begin{array}{c}\text { Action/ } \\
\text { meaningful responses }\end{array}$ \\
\hline Imperative & 70 & 100 \\
"Can you ..." & 59 & 90 \\
."Why don't you . ... & 65 & 100 \\
"Do you want to ..." & 64 & 94 \\
"Can" + noun & 58 & 83 \\
"Does" + noun & 55 & 85 \\
Declarative & 59 & 88 \\
"May you ..." & 62 & 87 \\
\hline
\end{tabular}


mood of the input sentences is discredited by the fact that imperatives, interrogatives, and declaratives all received many action responses from all the subjects. Nevertheless, one can ask whether there are other markers which might encourage a child to deviate from the procedure of action responding. A variety of hypotheses concerning the kinds of linguistic markers that might function as such "action inhibitors" were examined both within subjects and within groups.

If a child assumes that utterances with rising intonation may require an informing response, then, in a relatively neutral context, each of the question types should elicit an informing response at least once. None of the children followed such a pattern of producing at least one informing response to each of the question types. Even excluding "Why don't you ....," which one can argue is rarely meant literally and may be learned as an idiomatic imperative, one finds no evidence for the intonational cue hypothesis.

Another possibility is that the absence of "you" acted as a stop-action cue in sentences not having an action word in the initial position. This possibility is discounted for the younger groups because they produced no informing responses to the declarative. For the high group, three children produced at least one informing response to each of the three sentence types not containing "you," but each also gave one informing response to a sentence containing "you." Therefore, the "absence of you" cue cannot fully account for their behavior.

Alternatively, children may notice that the declarative is a type of sentence which often requires no overt response on their part except attention to the objects or activities referred to in the speech they hear. None of the children in the two younger groups produced any such behavior in response to the declarative, but five of the children in the high group did so once, and one did so twice. Table 4 illustrates that for no other sen-

TABLE 4

Number of Subjects in Each Group Who Gave at Least One Informing Response to a Sentence TyPe, Experiment 1

\begin{tabular}{lccc}
\hline & \multicolumn{3}{c}{ MLU group } \\
\cline { 2 - 4 } Sentence type & Iow & Middle & High \\
\hline Imperative .. & 0 & 0 & 0 \\
"Can you ..." .. & 1 & 1 & 1 \\
"Why don't you . . . & 0 & 0 & 0 \\
"Do you want to ... & 0 & 1 & 3 \\
"Can" + noun & 1 & 2 & 5 \\
"Does" + noun & 1 & 2 & 4 \\
Declarative & 0 & 0 & 6 \\
"May you . . . & 1 & 2 & 3 \\
\hline
\end{tabular}


tence type did every subject in a group produce at least one informing response. Here, then, is some evidence that children who can put together fairly complete sentences may be growing more sensitive to the grammatical features of sentences as clues to appropriate responding. ${ }^{5}$

Nevertheless, in a situation where contextual cues had been minimized and the surface features of the sentences could have been considered the best guide to the required response, the children's response patterns indicated little overall sensitivity to general syntactic differences among the sentences. Instead, children may gradually learn that in certain contexts some sentences are not appropriately answered by action, and they learn this by occasionally hearing those sentences in just such situations. In fact, the two sentence types which elicited no informing responses at all, the imperative and the "Why don't you," are just the ones children would most likely hear only in directive contexts. Apparently, children need not learn which sentences require action responses, since they all do at the earliest stages; and those for which the children receive no counter evidence simply continue to do so. The final prediction receives support in that no unique set of linguistic markers examined seems to be the source of that counter evidence.

\section{Summary}

The results of this first experiment have shown that, even in a neutral situation, children produce a preponderance of action responses to a variety of sentence types, some of which are typically considered to be requests for action only rarely (e.g., "May you . . ."). Moreover, scntence types differ little with regard to the likelihood they will elicit action responses. The more sophisticated the children in terms of their productive language capacity, the more likely they are to produce an occasional informing response, but there is no apparent unique set of linguistic markers that will lead children to produce informing as opposed to action responses in this neutral situation. These results, together with those of Shatz (1978), suggest that young children come to the communicative situation strongly biased to respond to language with action. The next experiment explores the nature of this bias and tests the strength of it in different contexts.

\section{EXPERIMENT II: THE EFFECTS OF CONTEXTUAL SET}

Sentences that can be taken in more than one way were presented in two different contexts, one supporting a directive interpretation and one sup-

\footnotetext{
s Of course, with the data at hand, one cannot determine the relative utility of several possible cues. Some children may have noted that sentences with initial-position the often do not require action, whereas others may have focused on intonation differences. Moreover, since most of the high-group children also produced occasional informing responses to other sentence types, factors additional to those peculiar to declarative forms are necessary to account for the data in Table 4.
} 
porting an informational interpretation. While the two contexts supported different interpretations, neither one completely prohibited action or informing responses. Subjects were presented with the same or equivalent test sentence twice, but each time the test sentence was preceded by different "setting" sentences, to which subjects were expected to have responded differentially.

From the model presented earlier, several predictions were made about young children's response behavior in these circumstances.

(a) For those children who have given evidence of the ability to produce an informing response, the tendency to produce such responses increases in contexts supporting them.

(b) While an informational context enhances the tendency to produce informing responses, children are still less likely to produce informing responses in an informational context than they are action responses in a directive context, given sentences that can be taken in more than one way.

(c) The direction of development is toward a greater influence of context on responses to sentences that can be taken in more than one way. That is, the more sophisticated children are more likely to produce informing responses in the appropriate context than are the less sophisticated children.

Obviously, at some very early stage young children are incapable of making informing responses, but the proposed model predicts that even children who can produce such responses do so only under very limited circumstances: When they are stopped from responding with action either by physical, social, or interpersonal constraints or by virtue of having learned a linguistic routine in which an alternative reply is required. Hypothesis (c) follows not from the assumption that more sophisticated children will have an easier time producing informing responses, but from the notion that they will have learned more about the social or linguistic environments requiring them. Given the low requirements for producing an informing response, it is unlikely that a response difficulty hypothesis could account for the predominance of action responding. Nevertheless, the question was investigated further by examining the frequency of informing responses to the relatively unambiguous setting sentences. Thus, the experiment tested both the response difficulty hypothesis as well as hypotheses (a)-(c).

\section{Method}

Design. A subset of sentence types used in the first experiment was used to generate a list of test sentences: (1) "Can you . . . ," (2) "Can" + noun . . . , (3) the declarative, and (4) "Why don't you. . . .". The test sentences were preceded by either three or four direct imperatives to foster a directive interpretation or three or four informational questions or statements to foster an informational interpretation. The combination of a series of setting sentences plus a test sentence was called a sequence. Thus, there were directive sequences and informational sequences. The setting sentences chosen for informational sequences either referred to actions that were not possible in the physical context ("Can Daddy talk on the telephone?" when the father was absent) or referred to properties of 
TABLE 5

EXamples of Directive and Informational Sequences in the Contextual Set Experiment

\begin{tabular}{|c|c|c|}
\hline & Directive sequence & Informational sequence \\
\hline Introductory & & $\begin{array}{l}\text { Who talks on the telephone } \\
\text { in your house? }\end{array}$ \\
\hline Setting sentences & $\begin{array}{l}\text { Come get the telephone. } \\
\text { Push the button. } \\
\text { Find the "one." } \\
\text { Ring the bell. }\end{array}$ & $\begin{array}{l}\text { Can Mommy talk on the } \\
\text { telephone? } \\
\text { Can Daddy talk on the } \\
\text { telephone? } \\
\text { Can (sibling or pet) talk on } \\
\text { the telephone? } \\
\text { Can a dolly talk on the } \\
\text { telephone? }\end{array}$ \\
\hline Identical test sentence & $\begin{array}{l}\text { Can you talk on the } \\
\text { telephone? }\end{array}$ & $\begin{array}{l}\text { Can you talk on the } \\
\text { telephone? }\end{array}$ \\
\hline Introductory & Let's play a game. & \\
\hline Setting sentences & $\begin{array}{l}\text { Touch your nose. } \\
\text { Clap your hands. } \\
\text { Show me your tongue. } \\
\text { Stand up. }\end{array}$ & $\begin{array}{l}\text { Is this an apple } ?^{a} \\
\text { What is this? } \\
\text { Is this fruit? } \\
\text { Is this yellow? }\end{array}$ \\
\hline Nonidentical test sentences & Can you jump? & Can you eat this apple? \\
\hline
\end{tabular}

"Toy was a plastic apple with other "fruits" nested inside it.

objects with no mention of action ("Is this red?"). The setting imperatives, of course, all explicitly requested action.

Three of the four test sentence types appeared in both directive and informational sequences. "Why don't you . . ." appeared just in two informational sequences. That type was the only indirect directive in the earlier experiment that had elicited no informing responses at all. It was included here to see whether informing responses to it could be elicited in supportive situations or whether children would show no ability to produce even "because" as a response ${ }^{6}$ Since the other sentence types had elicited informing responses, the "Why don't you ..." sentences were treated separately so as not to confound the question of response difficulty with the effect of context.

For the other three sentence types, there were six trials each, half in each type of sequence, for a total of 18 sequences. Within sequence types, each trial of a given sentence type utilized different setting sentences, content words in the test sentence, and accompanying toys. Across sequence types, each trial of a given sentence type differed on setting sentences but not necessarily on toys or content words. Table 5 illustrates identical test sentences that occurred in both types of sequence and nonidentical sentences that occurred in only one. Two sets of the "Can you . . ." and "Can" + noun . . . sequences and one of the declaratives utilized identical sentences. Also illustrated in Table 5 are "introductory" sentences which were used occasionally to help set the scene and assure the nonambiguity of the setting sentences.

${ }^{6}$ Ervin-Tripp (1970) found that 2-year-olds interpreted "Why don't you . . ." as a call to action, "and if there was no way to perform the response, they did not reply." 
Subjects were assigned to one of two language sophistication groups on the basis of their productive language ability. All subjects heard all 18 sequences. The subjects almost always had some toy to which the sentences referred and which they could manipulate. (The lone exception is the jump sequence in Table 5.) A single order for presentation of sequences was devised which sought to maintain the child's interest and the naturalness of the situation while mingling the two kinds of sequences throughout. [See Shatz (Note 5) for details.]

Subjects. The subjects were 13 of the children who had participated in the neutral condition experiment. The five children who had given no informing responses at all in Experiment 1 were not included since the likelihood of getting sufficient appropriate responses from them on the setting sentences seemed small. The remaining children were divided into two groups on the basis of the language samples collected earlier: one of seven children with MLU values of less than three words per utterance (mean $M L U=2.1$ ) and the other of six children with MLU values of more than three words per utterance (mean MLU $=3.5$ ).

Toys. The toys were commercially available small toys and picture books appropriate for young preschoolers.

Procedure. Within a week after the child had participated in the first experiment, the second experiment was videotaped in the subject's home. The experimenter invited the subject to join her on the floor together with a large bag containing 12 envelopes, each with a toy or set of toys in it. The experimenter presented the toys from one envelope at a time to the child, who was given a few minutes to manipulate the toys before the experimenter uttered the initial sentence of the first sequence related to those toys. ${ }^{\text {? }}$

The experimenter followed introductory sentences immediately with the first setting sentence without allowing for a response. After each setting sentence, the subject was given an opportunity to respond, but one setting sentence followed fairly quickly upon the last. If the child's attention wandered, or the play session was interrupted, the experimenter attempted to give the subject the same total number of setting sentences as he or she would have had without interruption. The experimenter spoke no other sentences once a sequence was begun except for occasional words of reinforcement or short replies to the child's comments, nor did she challenge or question responses. Setting sentences not responded to were repeated once.

The experimenter used several nonverbal and parasyntactic devices to facilitate the intended interpretations of the setting sentences. For example, for an informational sequence on dolls fitting in swings, the experimenter picked up and showed each doll to the subject as she spoke, shaking her head in appropriate ways while uttering sentences like "It can fit in the swing" or "This doll can't fit in the swing." For imperatives, the experimenter might point to the referent. Also, the setting sentences were spoken in as natural a manner as possible with the intention and intonation appropriate to the type of sequence.

The test sentence followed immediately upon the child's response to the last setting sentence of a sequence. It was spoken with the intonation appropriate to the intention, but nonverbal cues were avoided. A test sentence receiving no response was repeated once.

When the child had responded to the last test sentence relating to particular toys, the experimenter would pull out another envelope and begin a new sequence. If a child became uncooperative, particular toys or sequences would be eliminated. The average number of sequences presented per child was 17, out of a possible 18 (excluding the two "Why don't you ... ."sequences). Approximately $40 \mathrm{~min}$ were required to present the entire protocol.

${ }^{7}$ Occasionally, during this time, the child did just the activity relevant to the sequence. If this happened, the subject completed the activity, and the experimenter then placed the toys where she wanted them and began the sequence. Thus, it is likely that later actions were actually responses to test sentences and not just actions a more restrictive procedure might have prohibited earlier. 


\section{Data Analysis}

The children's responses to hoth the setting sentences and the test sentences were coded according to the categories described earlier. Scores on the following measures were then computed for each subject: (1) for setting sentences, the proportion of all responses to directive setting sentences that were action responses and the proportion of all responses to informational setting sentences that were informing responses (i.e, , the proportion for each kind of setting sentence that was answered "appropriately"); (2) for each type of sequence, the proportion of sequences "passed," that is, the percentage in which the subjects had responded appropriately, as in 1, to three out of four or two out of three of the setting sentences; and (3) for the test sentences, the $\mathrm{A} / \mathrm{T}$ and $\mathrm{A} / \mathrm{M}$ measures described earlier were again used, but these utilized only the responses to test sentences occurring in passed sequences, where subjects could be considered to have been "set" to respond in one way or another. An I/T score, the percentage of total responses that were informing responses, was similarly calculated.

The reliability of code assignment was checked as before by having two coders independently code some of the transcripts. The agreement between coders on eight randomly selected transcripts was $\mathbf{8 2 \%}$. Disagreements were discussed and resolved.

\section{Results and Preliminary Discussion}

The "Can you . . .," "Can" + noun . . ., and Declarative Sequences

Setting sentences. The responses to the setting sentences revealed that even the less competent speakers had little difficulty producing both kinds of responses when called for. The more sophisticated group responded with action $88 \%$ of the time to imperatives, whereas the less sophisticated group did so $84 \%$ of the time. In response to unambiguous informational sentences, the higher group produced $85 \%$ informing responses, the lower group, $82 \%$. Neither the between-group or within-group differences were significant. Thus, children producing at least one but never very many informing responses in the neutral context of the first experiment had no difficulty producing those responses abundantly in situations in which both sentence and nonverbal context clearly called for them. At least for children with this amount of productive ability, the strong tendency to action responding found earlier is not attributable to an informing response deficiency.

Not surprisingly there was also no difference between groups with regard to scores for passing sequences of either kind. Table 6 summarizes

TABLE 6

Average Percentage of Sequences Passed, Experiment 2

Type of sequence

MLU group

Directive Informational 
the scores. While the between- and within-group differences were not significant, there was some tendency overall for the children to pass more directive sequences than informational ones $[t(12)=1.86, p<.10]$.

Test sentences. The $t$ tests on the likelihood of responding with action to nonidentical versus identical test sentences for each of the two kinds of sequences showed no differences between identicals and nonidenticals, nor was there any evidence that the first response to an identical sentence influenced the nature of the response to the second occurrence of that sentence. Therefore, the data on nonidentical and identical sentences were combined for the remaining analyses.

Only five children produced one informing response each in answer to all the test sentences in directive sequences. The remaining eight children produced none. In contrast, every child produced at least one informing response to the test sentences in informational sequences. Table 7 shows that for the combined groups the average proportion of $1 / T$ responses in the informing sequences was $46 \%$. Thus, the first prediction is confirmed in that an informational context enhanced the production of informing responses.

It can be seen in Table 7 that the children produced a higher proportion of action responses in the directive sequences $(68 \%)$ than informing responses in the informational sequences $(46 \%)[t(12)=2.98, p<.01$, one tailed]. Moreover, an action response "error" was much more likely to occur in an informational sequence (31\%) than was an informing response "error" in a directive sequence (5\%). These results are just the ones predicted for listeners whose primary mode of responding is action and who have to be detoured from it by specific cues.

The final prediction concerned the direction of development away from action and toward informing responding in the informational context. Table 7 also shows the proportion of meaningful responses that were action responses for the two kinds of sequences for the two groups of children.

TABLE 7

Average Percentages of Action and Informing Responses to Test Sentences, Experiment 2

\begin{tabular}{lcc}
\multicolumn{1}{c}{ Measure $^{a}$} & \multicolumn{2}{c}{ Type of sequence } \\
\cline { 2 - 3 } & Directive & Informational \\
\hline Action/total & 68 & 31 \\
Informing/total & 5 & 46 \\
Action/meaningful & & 53 \\
$\quad$ Less than three words group & 90 & 28 \\
$\quad$ More than three words group & 94 & \\
\hline
\end{tabular}

${ }^{a}$ MLU groups are combined for the $\mathrm{A} / \mathrm{T}$ and $\mathrm{I} / \mathrm{T}$ measures. 
While the groups did not differ on the directive sequences, the more advanced children produced fewer action responses $(28 \%)$ on the informational sequences than did the less sophisticated children (53\%) (MannWhitney $U=2, p<.01$ ). As predicted, the more sophisticated children were influenced more by the nature of the preceding conversation.

Again, the "yes" + action responses were counted to check on possible effects of the coding scheme. In the directive set $18 \%$ of the action responses were of this type, and in the informational set $17 \%$ were. Since the more sophisticated children produced twice as many of these responses as did the less sophisticated group, the developmental trends already shown would have been stronger still under a coding scheme counting "yes" + action as an informing response.

Had the more sophisticated listeners acquired some syntactic knowledge that fostered informing responses in the informational set? Table 8 shows that on the average the more sophisticated group produced fewer action responses (and hence more informing responses) than the less sophisticated group for each of the sentence types. However, only the difference for "Can you ...". is significant by a Mann-Whitney test $(U=2$, $\mathrm{p}<.01$ ). The within-group differences between types are not significant. An analysis of responses by sequence for each of the two kinds of sequence revealed no significant effect of particular sequence on responses. Thus, while on the whole the children were not terribly consistent in the way they responded to one type of sentence versus another, or one sequence versus another, there was a tendency for the lower group to respond more with action to the "Can you . . ." sentences and for the higher group to give informing responses to them. Possibly the presence of you encouraged poor speakers to respond with action but adept speakers were more influenced by previous conversation. In any case, again the influence of mood was minimal, nor did any obvious set of surface linguistic features account for the observed response patterns.

Finally, it is unlikely that the observed differences in response patterns for directive versus informational sequences are due solely to differences in the intonation with which test sentences were spoken in the two kinds

TABLE 8

Average Percentage of Meaningful Responses to Three Sentence Types in Informational Sequences That Were action Responses, Experiment 2

Type of sentence

MLU group "Can you" "Can" + noun Declarative


of sequence. In an experiment on intonation (Shatz, Note 5), adult subjects heard apart from context only the test sentences, which had been transferred to audiotape from the videotapes. They could not determine at a level significantly greater than chance which utterances had been intended as directives and which as informationals. Thus, it is improbable that the children in the contextual set experiment used only the parasyntactic information available in the test sentences when selecting their responses. It is possible, however, that the maintenance of intonation or stress patterns from setting to test sentence encouraged some children to rely on prior conversation in constructing an interpretation.

"Why don't you . . ." Sequences

The first of the two informational "Why don't you . . ." sequences included declarative setting sentences to which the children simply had to attend. The test sentence, "Why don't you jump rope?" was said in the absence of a jumprope, in order to help foster the informational interpretation. ${ }^{8}$ All 11 subjects who heard this sequence passed the setting sentences, but the two MLU groups' responses to the test sentence were quite different. Two of the five less adept speakers literally jumped in response to the sentence; the other three said "no" or did nothing. Only one subject in the higher group gave such a response. Four others answered by providing reasons for not doing the action, e.g., "I don't have rope." One corrected the experimenter by saying, "I can jump!" None of the children used the word because in their responses.

The second of these sequences utilized "Why don't you . . ." sentences for both setting and test sentences. The setting sentences were "defective" as requests for action in that the acts requested were not feasible (cf. Searle, 1975), and hence the only reasonable interpretation was informational. Surprisingly, half of the children attempted the actions proposed in the setting sentences. They would put their feet to their ears in response to "Why don't you wear your shoes on your ears?" or their heads toward the floor in response to "Why don't you walk on your head?" and none of them seemed to be joking. The remaining children looked puzzled. One girl repeatedly asked "What?" Two low-group children gave corrections as reasons, such as "Drink milk" in response to "Why don't you drink cookies?"

The paucity of such linguistically simple but quite adequate informing responses suggests that the children's poor performance was due more to cognitive difficulties than to productive linguistic deficiencies. Most of the children could have easily produced two-word utterances like "Drink milk," but they generally did not seem able to justify verbally the impossibility or

\footnotetext{
${ }^{8}$ Note that using physical context to support the intended interpretation of the test sentence is a departure from standard procedure.
} 
implausibility of an action except by referring to their own inability to do the act. Perhaps "you" constrained the interpretation specifically to the self, or perhaps the children had no notion that talk can be about the feasibility of actions in general. Again, none of the children prefaced their remarks with "because."

Given the children's responses to the setting sentences, it is not surprising that many of them responded to the test sentence with action as well. Only three of the higher group children gave reasons for not doing the action. Again, "because" did not occur as a response. In general, then, the results on the "Why don't you . . ." sentences corroborate the earlier results. If actions are at all possible as responses to speech, then children will try to perform them. But "Why don't you . . ." seems especially conducive to action interpretations, even though children of this age have been reported to know that "why" questions can be answered with "because" (Ervin-Tripp, 1970). It may be that children learn the "why . . . because" sequence as a routine before seeing any relation at all between the "why" and "why don't you" forms.

\section{Summary}

In situations where sentence and context work together to preclude action interpretations and support informing responses, children who have the ability to produce informing responses will do so. Therefore, children's predominance of action responding in more ambiguous situations cannot result from difficulty in producing informing responses. The notion that action is the basic mode of response is again supported in several ways: (1) Children produce more action responses in directive contexts than informing responses in informational contexts; (2) they make more action response "errors" in informational contexts than informing response "errors" in directive contexts; and (3) more sophisticated children produce more informing responses in informational contexts than do less sophisticated children. A subtle kind of context, that provided by prior conversation, gradually exerts more influence on the developing child's responses to sentences that can be taken in more than one way.

\section{GENERAL DISCUSSION}

\section{The Origins of the Response System}

I began with the following claim: Children's apparent understanding of messages more linguistically sophisticated than those they can produce stems from their strategy of relating language to plausible and possible actions in the world. Their interpretations of messages are constrained not only by linguistic information but also by contextual information and by their representational capacities. I have examined their responses to a 
variety of sentence types in a naturalistic setting (Shatz, 1978) as well as in a neutral setting and in two settings (directive and informational) designed to foster particular interpretations. In each of these situations the children showed strong tendencies to consider action a necessary part of their responses. Taken together, these studies support the view that children first deal with language as a specifier of requisite actions appropriate to the context in which linguistic interaction takes place. One need not grant children more to explain their performance as listeners.

Moreover, the notion that children first comprehend language in terms of its relationship to immediately possible actions on the world is consonant with recent proposals (e.g., Bates et al., 1975; Edwards, Notc 2) that early speech productions mainly encode action-based relationships. The developmental trends reported here demonstrate that children who evidence a broader understanding of the various messages language can convey also have better productive abilities. While these sorts of evidence do not confirm a single causal basis for both understanding and production, surely the child's preoccupation with action relations in the world is one important determinant of both what he understands and what he produces.

The assumption that the linguistic signal is only one of several sources of information available in the communication setting for the interpretation of messages is hardly a controversial one. More at issue is the nature of and the relationship between the representations of linguistic information and contextual information. Searle's pragmatic theory (Searle, 1970, 1975) suggests a psychological model in which the listener necessarily derives from the semantic and syntactic aspects of a sentence its literal meaning and then tests that for plausibility against contextual knowledge. ${ }^{9}$ If literal meaning is basic to any further interpretation of utterances, then one of the first tasks facing the child just acquiring language should be to discover which speaker intentions are directly expressed by which grammatical forms. One might then expect the child to respond to language first on the basis of these direct intention-grammar mappings, but the work presented here offers no evidence that the development of message interpretation progresses from a stage of assigning literal meanings to utterances to a stage in which indirect meanings can be assigned. While the work does not bear directly on the question of whether a purely linguistic representation is necessarily accessed in adult processing, it does discredit one theory of the development of message interpretation compatible with speech act theory. Moreover, it suggests that, at least for young children, general cognitive strategies for dealing with communicative situations play a more central role in assigning meaning to messages than do strictly grammatical considerations.

\footnotetext{
${ }^{9}$ It should be noted that Searle himself makes no claim to having a psychological theory.
} 
Just as there is no justification for assigning the primary basis for responding to grammatical knowledge, there is also no reason for rooting it in a prelinguistic understanding of speaker intentions. Although children demonstrate their own various intentions in prespeech or early speech behavior (Bates, et al., 1975; Dore 1974), such behavior offers no justification for granting them an understanding of the intentions of others. The response heuristic proposed here is not a mechanism for assigning speaker intentions. Rather it is an initial plan for producing responses to language which relate to the immediately perceptible world upon which the child can act. That early strategy limits the child to what Searle has called a words-to-world mapping (Searle, 1976), without entailing a claim that the child understands directive intentions better than or before informational ones, or even that he understands intentions at all. The proposals made here simply need not appeal to intention as an explanatory device for characterizing the interpretations of messages that seem to underlie children's response behavior. This conclusion has been influenced by the conservative principle of assuming as little ability as necessary to account for the children's behavior. While children, like adults, have been assumed to interpret messages with regard to their plausibility in context, plausibility need involve only a measure of the simplistic relation between the words heard and immediately possible actions. ${ }^{10}$

\section{Is the Predominance of Action Responding an Artifact?}

Although the tendency to respond with action has been well established, one can question whether responses are reliable indexes of listeners' interpretations of messages, for a response may reflect how an utterance influences a listener as well as how it has been interpreted. Austin (1962) took account of this difference between the effect of an utterance and the understanding of it when he distinguished between perlocutionary force and illocutionary force. According to Austin, an utterance may have consequences for a listener's behavior that are independent of the speaker's intending them. For example, suppose a speaker announces plans to buy a certain book, intending only to inform the listener of the future purchase. The listener responds by offering to lend the speaker a copy of the book. The perlocutionary effect of the initial statement is the offer of lending although the original illocutionary act was a statement of intent to buy and not a request to borrow. The listener's response may index a misunderstanding of the statement as a request, or he or she may have correctly understood it as a statement and decided on his or her own

\footnotetext{
${ }^{10}$ Searle uses the direction of mapping as a criterion for calegorizing illocutionary acts. His concern is for the mapping intended by the speaker, whereas mine is with the operation carried out by a listener who may not even explicitly recognize speaker intentions.
} 
to make the lending offer. Hence, his response is not informative with regard to interpretation.

Reeder (Note 3) makes a similar point about children's interpretations of indirect directives. Using a clever technique involving forced choices of paraphrases, he shows that preschoolers understand the difference between informational and directive intentions even though they carry out the actions expressed in the utterances they hear regardless of the intentions behind the utterances. Thus, with a technique suitable for children older than my subjects, Reeder is able to show a sophistication of understanding that is not evidenced by the children's actions alone. It could be argued that, by examining only responses to speech, I have underestimated my subjects' understanding of speaker intentions and overestimated the significance of action responses.

If it were possible to use a technique like that of Reeder with 2-year-olds, then I might have found that children such as the oldest "2-year-olds" who participated here, did have the ability to understand speaker intentions. But evidence for an understanding of speaker intentions does not explain why action is so ubiquitous. Indeed, one may ask why Reeder's subjects produced actions in response to virtually all the utterances they heard even when those actions were neither requisite nor particularly appropriate to the speaker's intentions. Perhaps their tendency to respond to language by producing a words-to-world match was a vestige of the earlier response strategy.

Nevertheless, given that young children like to play with toys and that in both Reeder's and my situations they were allowed to do so, one can ask whether action responding was supported to an unusual degree by the availability of toys. Several kinds of evidence argue against this notion. For one thing, the children did not just play haphazardly with the toys. They tried to produce actions related to the utterances they heard. Second, in the contextual set experiment, one of the directive test sequences urilized no toys. Even without toys to act on, all 12 of the children who heard that sequence produced an action response to the test question, "Can you jump?"; not one produced an informing response. Also, the "Why don't you . . ." setting sentences, despite their lack of feasibility, produced quite bizarre attempts at action more often than informing responses. The children seemed determined to produce action in response to speech if at all possible.

Moreover, if the children had actually taken more of the test utterances to carry informational import, they could have given more informing responses regardless of their activities with the toys. The coding scheme did not assign merely any behavior pattern involving action to the action category. Both the verbal and nonverbal behavior of the child had to be consistent with such an assignment. The children produced considerable amounts of speech during the interactions with adults but, as noted 
earlier, much of it was superfluous to the analysis of interpretation. They had the ability to produce more informing responses, but they did not.

Finally, other investigators have also recorded young children's tendencies to respond with action under a multiplicity of conditions varying from natural to quasi-experimental settings (Bloom, Rocissano, and Hood, 1976; Clark, Hutcheson, and van Buren, 1974; Ervin-Tripp, 1970; Wetstone and Friedlander, 1973).

\section{Developing into a Competent "Understander"}

How might children with only minimal abilities develop into more competent communicators? It seems reasonable to consider that experiences in communicative situations like those described earlier are important factors. For it is there that children will find times when the action-based strategy is inappropriate or insufficient for dealing with the demands made upon them. Speakers sometimes intend listeners to do things and signal those intentions in messages involving speech. In those cases, words-to-world mappings generate appropriate responses, but speakers can have other intentions as well. I have suggested several possible ways children might gradually come to recognize these cases via linguistic and contextual stop-action markers. The identification of stop-action markers and data on their acquisition and effect upon response behavior would obviously lend credence to the developmental model proposed here. One bit of favorable evidence comes from Ervin-Tripp's report (1970) that some children respond stereotypically to certain question words although they do not yet understand what the speaker intends to receive in the way of information. Apparently such children utilize the linguistic marker as a signal that action is inappropriate and are testing an alternative strategy for staying in the interaction.

Another avenue to development may be more direct feedback. When mothers are aware of their children's misrepresentations, they may initiate "repair" sequences which attempt to correct misunderstandings. Investigation of this possibility is currently underway.

Whatever the mechanisms of development, one thing is clear: Children make much progress at becoming good "understanders" during their early years. Both the behavior of the older subjects in these studies and the work of Reeder (Note 3) and Garvey (1975) provide evidence of that. But rapid achievements should not mislead us into denying the possibility of humble beginnings. My theory accounts for a considerable amount of early response behavior while granting children only those capacities that seem reasonable, given our knowledge of cognitive development and of adult comprehension processes.

Children try to participate in conversation even before they know much about speaking the language, and they do so by using a simple response 
strategy that utilizes what they know best. By regularly intending messages requiring responses consonant with that strategy, parents encourage their children's efforts and in the bargain are deceived by the children's apparent competence at understanding. However, misunderstanding that their children understand may be a merciful palliative for parents. It would indeed be difficult to admit of a communications generation gap at so tender a stage of parent-child relations.

\section{REFERENCES}

Austin, J. How to do things with words. Cambridge: Harvard University Press, 1962.

Bates, E. Language and context: The acquisition of pragmatics. New York: Academic Press, 1976. (a)

Bates, E. Pragmatics and socio-linguistics in child language. In D. Morehead \& A. Morehead (Eds.), Language deficiency in children: Selected readings. Baltimore: University Park Press, 1976. (b)

Bates, E., Camaioni, L., \& Volterra, V. The acquisition of performatives prior to speech. Merrill-Palmer Quarterly, 1975, 21, 205-226.

Bloom, L. Talking, understanding, and thinking. In R. Schiefelbusch \& L. Lloyd (Eds.), Language perspectives-Acquisition, retardation and intervention. Baltimore: University Park Press, 1974.

Bloom, L., Rocissano, L., \& Hood, L. Adult-child discourse: Developmental interaction between information processing and linguistic knowledge. Cognitive Psychology, $1976,8,521-552$.

Bransford, J., \& McCarrell, N. A sketch of a cognitive approach to comprehension: Some thoughts about understanding what it means to comprehend. In W. Weimer \& D. Palermo (Eds.), Cognition and the symbolic processes. Hillsdale, NJ: Erlbaum, 1974.

Broen, P. The verbal environment of the language-learning child. American Speech and Hearing Association Monographs, 1972, No. 17.

Bruner, J. The ontogenesis of speech acts. Journal of Child Language, 1975, 2, 1-20.

Clark, E. Nonlinguistic strategies and the acquisition of word meanings. Cognition, 1973, 2, 161-182.

Clark, H. H., \& Lucy, P. Understanding what is meant from what is said: A study in conversationally conveyed requests. Journal of Verbal Learning and Verbal Behavior, $1975,14,56-72$.

Clark, R., Hutcheson, S., \& van Buren, P. Comprehension and production in language acquisition. Journal of Linguistics, 1974, 10, 39-54.

Dore, J. A pragmatic description of early language development. Journal of Psycholinguistic Research, 1974, 4, 423-430.

Dore, J. "Oh them sheriff": A pragmatic analysis of children's responses to questions. In C. Mitchell-Kernan \& S. Ervin-Tripp (Eds.), Child discourse. New York: Academic Press, 1977.

Ervin-Tripp, S. Discourse agreement: How children answer questions. In J. R. Hayes (Ed.), Cognition and the development of language. New York: Wiley, 1970.

Escalona, S. Basic modes of social interaction: Their emergence and patterning during the first two years of life. Merrill-Palmer Quarterly, 1973, 19, 205-232.

Fraser, C., Bellugi, U., \& Brown, R. Control of grammar in imitation, comprehension and production. Journal of Verbal Learning and Verbal Behavior, 1963, 2, 121-135.

Garvey, C. Requests and responses in children's speech. Journal of Child Language, 1975, 2, 41-60.

Gelman, R., \& Shatz, M. Appropriate speech adjustments: The operation of conversa- 
tional constraints on talk to two-year-olds. In M. Lewis \& L. Rosenblum (Eds.), Interaction, conversation, and the development of language. New York: Wiley, 1977.

Gleason, J., \& Wcintraub, S. The acquisition of routines in child language. Language in Society, 1976, 5, 129-136.

Goldin-Meadow, S., Seligman, M., \& Gelman, R. Language in the two-year-old: Receptive and productive stages. Cognition, 1976, 4, 189-202.

Gordon, D., \& Lakoff, G. Conversational postulates. Papers from the Seventh Regional Meeting of the Chicago Linguistic Society. Chicago: Linguistics Department, University of Chicago, 1971. Pp. 63-84.

Grice, H. P. Logic and conversation. In P. Cole \& J. Morgan (Eds.), Speech acts: Syntax and semantics, Vol. 3. New York: Academic Press, 1975.

Gunter, R. Sentences in dialog. Columbia, SC: Hornbeam Press, 1974.

Holzman, $M$. The use of interrogative forms in the verbal interaction of three mothers and their children. Journal of Psycholinguistic Research, 1972, 1, 311-336.

Huttenlocher, J. The origins of language comprehension. In R. Solso (Ed.), Theories in cognitive psychology. Potomac, MD: Erlbaum, 1974.

Katz, J. Semantic theory. New York: Harper and Row, 1972.

Katz, J. Propositional structure: A study of the contribution of sentence meaning to speech acts. New York: Harper \& Row, 1977.

Keenan, E., \& Klein, E. Coherency in children's discourse. Journal of Psycholinguistic Research, 1975, 4, 365-380.

Luria, A. The development of the regulatory role of speech. In R. Harper, C. Anderson, C. Christensen, \& S. Hunka (Eds.), The cognitive processes. Englewood Cliffs, NJ: Prentice-Hall, 1964.

Macnamara, J., \& Baker, E. From sign to language. In J. Macnamara (Ed.), Language learning and thought. New York: Academic Press, 1977.

Newport, E. Motherese: The speech of mothers to young children. In N. Castellan, D. Pisoni, \& G. Potts (Eds.), Cognitive theory: Vol. 2. Hillsdale, NJ: Erlbaum, 1976.

Piaget, J. The language and thought of the child. New York: Harcourt, Brace, 1926.

Piaget, J. The origins of intelligence in children. New York: International Universities Press, 1952.

Piaget, J. Play, dreams, and imitation. New York: Norton, 1962.

Rommetveit, R. On message structure. New York: Wiley, 1974.

Scollon, R. One child's language from one to two: The origins of construction. New York: Academic Press, 1977.

Searle, J. Speech Acts. Cambridge: Cambridge University Press, 1970.

Searle, J. Indirect speech acts. In P. Cole \& J. Morgan (Eds.), Speech acts: Syntax and Semantics, Vol. 3. New York: Academic Press, 1975.

Searle, J. A classification of illocutionary acts. In K. Gunderson (Ed.), Minne sota studies in the philosophy of science. Minneapolis, MN: University of Minnesota Press, 1976.

Shatz, M. Children's comprehension of their mothers' question-directives. Journal of Child Language, 1978, 5, 39-46.

Shatz, M., \& Gelman, R. The development of communication skills: Modifications in the speech of young children as a function of listener. Monographs of the Society for Research in Child Development, 1973, 38, 5, pp. 1-37.

Snow, C. E. Mothers' speech to children learning language. Child Development, 1972, 43, $549-565$.

Wetstone, H., \& Friedlander, B. The effect of word order on young children's responses to simple questions and commands. Child Development, 1973, 44, 734-740.

Wilcox, S., \& Palermo, D. 'In', 'on' and 'under' revisited. Cognition, 1975, 3, 245-253. 


\section{REFERENCE NOTES}

1. Atkinson, M. Prerequisites for reference. Unpublished manuscript, University of Edinburgh, 1974.

2. Edwards, D. Constraints on actions: A source of early meanings in child language. Unpublished manuscript, Loughborough University, 1975.

3. Reeder, K. On young children's discrimination of illocutionary force: A report on work in progress. Unpublished manuscript, University of Birmingham, 1975.

4. Remick, H. The maternal environment of linguistic development. Unpublished Ph.D. dissertation, University of California, Davis. 1971.

5. Shatz, M. On understanding messages: A study in the comprehension of indirect directives. Unpublished Ph.D. dissertation, University of Pennsylvania, 1975.

6. Shatz, M. How' to do things by asking: Form-function relations in mothers' questions to children. Paper presented at the biennial meeting of the Society for Research in Child Development, New Orleans, March 1977.

7. Shatz, M,, \& Graves, Z. The role of maternal gesturing in language acquisition: do actions speak louder than words? Paper presented at the Boston University Conference on Language Development, October 1976.

(Accepted January 30, 1978) 